In memory of Professor David H. Jonassen, who has profoundly contributed to the theory and practice of education, and whose sudden departure from the physical realm has deeply saddened all of us. May he rest in peace!

\title{
Book Review: Learning with Technology - A Constructivist Perspective
}

\author{
Murat Ataizi \& Suleyman Ari \\ Anadolu University, Turkey
}

\section{Introduction}

This book (ISBN: 0-13-271891-X) is authored by David H. Jonassen, Kyle L. Peck, and Brent G. Wilson. It is published by Prentice Hall, Upper Saddle River, New Jersey, United States. In Learning with Technology, David Jonassen and his colleagues present a constructivist perspective of learning, beginning with a highly understandable explanation of constructivism. Throughout the book, the question they set out to answer is "how technology can best enhance meaningful learning?" The authors then go into justification for the constructivist use of technology in classroom and learning environments. The main technologies discussed in this book include video, hypermedia, e-mail, chats, bulletin boards, and simulations. The book provides various examples including suggestions about plausible learning procedures, roles of students, teachers, and assessment. The book also includes an index. At the end of each chapter, the references and ideas are presented. These ideas are designed in the form of questions.

In doing so, Jonassen and his associates in their constructivist approach, analyze and advocate a procedural account of learning that is different from the traditional styles of learning. Notwithstanding the focus of the book on technology, the authors also account for why the constructivist paradigm provides a more effective methodology for teaching students to think and learn all elements of education. We must highlight that though not new in the theory of knowledge, which is in epistemology, the constructivist paradigm is relatively new in the educational realm. Students of all educational backgrounds, academic worlds, and any classroom setting are the target audience of this book. Not only do the authors call for a revolution of the traditional dominant paradigm of education, but also they present ample evidence for the implementation of constructivism and technology in order to allow learners to construct knowledge, to think, and to learn. They argue that unlike what the traditional paradigm holds, technology does not teach thinking ability and knowledge. Rather, students only learn when they construct knowledge, think, and learn through meaningful experiences. For this reason, technology can be a means to support the process of meaning-making in an analytical way. Therefore, understanding does not come from technology but from the meaningful experiences of learners to which technology can only be a supportive tool. In the final analysis, the goal of the book is to call for an educational reform by employing a 
constructivist paradigm of learning. Ultimately, the book aims to provide an impetus for a shift in the dominant paradigm of education.

\section{Chapters}

In Chapter 1, the authors challenge the traditional view that people learn from technology. Conversely, the authors claim that people learn from thinking, and thinking mediates learning. Thus, learning is a product of thinking. The role of technology and teacher is indirect since they do not necessarily lead to thinking. Therefore, the authors argue that technology, along with teacher, can only be a tool and intellectual partner to support learning by affording assistance to students for thinking. The authors introduce the constructivist assumption about learning in that we learn from experiencing the object of analysis, whatever they may be, interpreting about them, reasoning about them, and reflecting upon them as a consequence. Thus, the authors borrow Jerome Bruner's (1990) conceptualization of the process, known as "meaningmaking", which is according to the authors at the heart of a philosophy of education called Constructivism. What follows logically is that according to constructivism, knowledge is constructed, not transmitted. According to the authors, knowledge construction results from a dissonance between what is known and what is observed in the world. In the constructivist paradigm, there are five interdependent attributes of meaningful learning, which are active, constructive, intentional, authentic, and cooperative formation of the learning process. Presumably, technology must be used to support these attributes of learning.

The authors, based on the hypothesis that technology can help learners engage in active, constructive, intentional, authentic, and cooperative learning, dedicate Chapter 2 to how the internet illustrates their argument. The internet can immerse students in stimulating, motivating, challenging, and vibrant learning environments whereby the computer literacy is obtained while achieving much higher goals. Therefore, the authors cite the list of habits of an educated mind as creativity, problem-solving, global consciousness, respectful skepticism, cooperation, responsibility, self-reliance, self-discipline, ethics, systems thinking, and conventional as well as technological literacy. The authors indicate that knowledge-building takes place through building things. According to them, the internet is an instrument to help the construction of such an illustrative process, just like in the case of building a web page. Furthermore, this chapter provides numerous examples of internet applications used in learning. To sum up, though not a meaning, the internet is a means to help individuals learn from their experiences.

Chapter 3 draws our attention to television as a very powerful medium of communication. Despite the original research data pointing out that television in education is as effective as traditional methods of learning, the authors state that television has very little effect on education while it has a profound impact on how we perceive the world. In order to cultivate the so-called effectiveness of television in education, a conscious, planned, and well-integrated educative tool should be implemented in the classroom environment. Unless learners engage in active, constructive, intentional, authentic, and cooperative experiences, television is bound to fail in educational practices. Furthermore, the danger is that television used randomly harms learners' cognitive and emotional abilities. Television is a powerful learning tool only when learners develop a critical approach towards television as a user and producer. Therefore, the authors suggest the use of video in education since producing video requires active, constructive, intentional, authentic, and cooperative involvement of learners. So, 
producing video is a more rewarding tool for learning within the scope of a constructively framed perspective of education compared to the random use of television.

After discussing the effects of hypermedia upon education, the authors point out in Chapter 4 that multimedia has become an essential component of corporate and educational communication. The multimedia which the authors emphasize is the enhancement of group and lecture presentations. Providing information in multiple forms makes the journey surely more interesting. Even so, the authors argue that just like any other learning tool, multimedia may turn out to be a cumbersome instrument in education if it is not used consciously and does not support meaningful learning. Therefore, it must be well-planned and supported to make sense through practices. As a consequence, both multimedia and hypermedia can be powerful instruments in education when they are used to support active, constructive, intentional, cooperative, and authentic learning. Otherwise, technology for the sake of technology would mean nothing.

In Chapter 5, the authors focus on the significance of the communities of practice in a complex society. They further provide examples to prove that learning naturally results from just participating in a community of practice. Therefore, building knowledge within a constructivist approach becomes a social activity rather than a solitary striving. For this reason, according to the authors, a constructivist use of technology plays a key role in the knowledge-building communities via providing a medium for storing, organizing, and reformulating the ideas that are contributed by each community member. Then, the authors constructively propose that the goal of schools should be to foster knowledge-building communities. The concepts of discourse community, community of practice, knowledge-building community, and learning community overlap to a large extent. Learning communities can help reform the schools. So that technology can be a supportive tool for learning communities. The use of computers and internet can be a real momentous support for enhancing learning and forming communities. At the core of communities, sharing is the very point of the relationship among teachers and students. Learning communities are united by a common cause of mutual support and by mutual values and experiences. Therefore, they have the intersubjective understanding of each other and the interactive fulfillment of their purposes and desires. In a nutshell, the current technological apparatus can provide an unusual opportunity for learning communities to unleash their both social and cognitive potential as illustrated in the use of the collaboratory notebook, which is shared by the whole group.

The authors re-emphasize in Chapter 6 that technology should be used as a knowledge construction tool that amplifies learners' abilities to construct knowledge for themselves rather than being taught by preprogramed lessons. Learners learn with technology, not from it, through meaningful activities. According to the authors, students learn with technology, such as computers used as cognitive tools, which the authors remark as mind-tools. To summarize, the authors argue that by using technology as mind-tools, students can further develop their creative, analytical, critical, problem-solving, decision-making, reasoning, intuitive, and self-regulating faculties. In this respect, when constructively used, technology can lead to the education of a more intellectual and competent generation of learners. An example of a mind-tool is a concept or semantic map, which helps learners understand complex matters in a spatial manner and see the relations amongst different elements of the object under examination.

Chapter 7 presents two examples of a constructivist learning environment, which is abbreviated as CLES, combining all the components of the constructivist learning paradigm 
within an integrated setting. Furthermore, the authors explain that learners learn by doing, that is by engaging in meaningful activities. By engaging in CLES, students explore, experience, construct, and reflect. CLES are defined as constructivist learning environments, in which technology is used as a mind-tool to help learners improve their meaning-making practices. As shown in Chapter 7, there are three integral components of a constructivist learning environment which are respectively named as the problem context, the problem presentation, and the problem manipulation. Deductively, using technology as a supportive tool in each of these components will improve the constructivist elements called active, constructive, cooperative, authentic, and intentional learning processes.

In Chapter 8, the authors first sum up their constructivist ideas about the use of technology in education proposed throughout the book. Second, they discuss some of the implications about adopting a constructivist philosophy for education. Third, they elaborate on how to interpret learning from constructivist practices of technology by offering rubrics for evaluating learning outcomes. To begin with, when it comes to the constructivist use of technology, technology should be used in the pursuit of meaningful learning, that is, in meaning-making. Considering the implications of a constructivist paradigm of education, it is assumed that the education system is going to shift. Hence, technology can be a supportive tool if used constructively. Teachers should be open to a new model of education in which they become coaches for students instead of the arbiters of knowledge. Students construct their own meaning of the world. When it comes to students, they should take more responsibility and more risks as well as more initiatives. In so far as evaluation is concerned, meaningful learning is authentic and consequently complex. Therefore, the authors call for an authentic assessment. For this reason, they suggest the use of rubrics for evaluating performance. A rubric, according to the authors, is a code or a set of codes designed to govern action. In the educational setting, the term has emerged to be used in the assessment of complex performances. In the final analysis, since a constructivist learning environment is a complex setting, the authors accept the use of rubrics as the proper mechanism of assessment.

\section{Conclusion}

In conclusion, in this book, the authors present us an alternative theory and practice of education, i.e. the constructivist paradigm which means to deepen and further the meaningful project of forerunners like John Dewey, Maria Montessori, and Jean Piaget. The book, that is full of insights and professional arguments, is highly readable and understandable. This book can be used as an instructive tool at any level of education from primary education to the postgraduate level. The only criticism that can be directed to this book is the ambiguity of the conventional paradigm of education expected to give up its historical sphere of influence to an alternate paradigm of education. Perhaps, the authors cognitively and intuitively assume that a better alternative world will take over naturally.

Ultimately, the most important parameter affecting our lives has probably been the system of education, regardless of time and space throughout history. In the midst of repercussions about how we should improve our education system, the authors' constructivist perspective can bridge the gap. After all, a different starting point, such as the constructivist paradigm of education, may lead to a better education system because the point is to let students enjoy and rule over their destinies by the virtue of a functional map throughout their educational journey. 
Correspondence: Murat Ataizi, Associate Professor, Faculty of Communication Sciences, Anadolu University, Yunus Emre Campus, Eskisehir, Turkey 